\title{
STUDENTS PERCEPTION OF GAMIFICATION TO PROMOTE CLASSROOM ENGAGEMENT AND MOTIVATION IN SENIOR HIGH SCHOOL
}

\author{
Gilang A. Pratama ${ }^{1}$ \\ Faculty of Teacher Training and Education ${ }^{1}$ \\ Ibn Khaldun University Bogor \\ gilangmymail@gmail.com
}

APA Citation: Pratama, G. A. (2020). Students perception of gamification to promote classroom engagement and motivation in senior high school. Language Research in Society Journal, 1(1), 58-68.

Received: 27 March 2020

Accepted: 16 April 2020

Published: 02 May 2020

Abstract: The development of English teaching and learning is also influenced by rapid changes in technology as we enter the industry of 4.0. Education and teaching-related field areas such as pedagogy, teaching media, the courses, etc. are the subjects which have been impacted by technology. Meanwhile, the lack of motivation is one of the obstacles that students faced. In this research, the researcher used one online-gamification tool called 'Kahoot!' in a senior high school to promote their engagement and motivation. The case study and questionnaire were used for the method of data collection. The data collection process was conducted for two months on campus. The meaningful gamification concept was applied through Kahoot! at the end of the meeting, and the last session they answered the questionnaires. Thirty-five students participated in this study, and the result of the study showed students' responses which are discussed under two main topics; Students' engagement and motivation, and learning outcomes.

Keywords: kahoot!; students' perception; classroom engagement; motivation

\section{INTRODUCTION}

The development of technology brings a new concept for educators in carrying out the learning activity. The needs of a new learning pedagogy which can accommodate millennials becomes one of the challenges that teachers face (Becker, 2017). Due to the fact that younger learners are very dependent on technology, almost all aspects of their life cannot be separated from technologies. Young learners can get information easily, share or update their activity through social media, they also spend a lot of time playing games online. However, this technology addiction cannot lead the learners to be successful in the classroom and sometimes it creates challenges in creating a good learning environment.

Most senior high school students who attend an English course are not interested in English because they might find English classes difficult and boring. Their difficulties in the learning process might be caused by the lack of vocabularies, low ability in grammar and spelling (Farooq \& Uzair-ul-hassan, 2012), unsupportive classroom environment (Khan \& Khan, 2016), and lack of motivation to study (Lo \& Hyland, 2007). 
In line with the above phenomena, teachers find that students are more interested in using their mobile phones for playing games than they do for studying. Khan and Khan (2016), in their study, also found that motivation is an obstacle. They say that some students are motivated while numerous of the respondents are not interested to learn English because of different factors. It shows the students are motivated, but they do not look motivated due to the absence of many learning needs. The findings of the study implied that there is a need amongst students to create motivation. McGonigal (2011, p. 75) argued that games could be the solution for millennials in the classroom: "Educational games are at best a temporary solution. The engagement gap is getting too wide for a handful of educational games to make a significant and lasting difference".

One alternative is online gamification. One of the online gamifications that is suitable and relevant in enhancing student motivation is Kahoot!. It allows the educator to create surveys and game-based quizzes that they can join in the game with PIN. While this argument focuses on the important role that teachers play in successfully integrating technology into classroom language teaching, an interesting question comes: "What do students' perception of the latest gamification tools to promote students' motivation in their language classroom experiences?"

\section{THEORETICAL FRAMEWORK}

\section{Engagement and Motivation}

The concepts of academic motivation and engagement might have much in common, leading to ambiguity. To get in-depth knowledge, in this case, the theory of motivation defines motivation as an attribute of its source to internal drives to meet the underlying psychological needs, such as the need for competence, autonomy, and connection (Christenson et al., 2012). On the other hand, engagement is defined as psychological investment by the student in and efforts aimed at learning, understanding or mastering the knowledge, skills or crafts designed to promote academic work. It is important to note that the same problem exists in the field of achievement motivation. This area of psychology is also pervaded by the tension between broad, inclusive versus more specific perspectives (Christenson et al., 2012).

Drawing on the theory above regarding academic motivation and a very vague concept of engagement, it is impossible to address the issue of whether motivation should be regarded as part of the engagement or vice versa. Christenson et al. (2012, p. 138) illustrated this case like, "at the most general level, we can say motivation influences behavior which, in turn, influences subsequent outcomes or $\mathrm{A} \rightarrow \mathrm{B} \rightarrow \mathrm{C}$, with $\mathrm{A}=$ motivation, $\mathrm{B}=$ behavior, and $\mathrm{C}=$ let us say, learning. $\mathrm{C}$ of course could also be high school graduation, GPA, etc. Such a model seems quite satisfying because it is general and because it makes clear the mediating role of behavior." Thus, they concluded the role of motivation and engagement as "in the general case, one could say that $\mathrm{B}$ is engagement. If so, then motivation leads to engagement; motivation is thus a precursor of engagement rather than a part of engagement, and engagement mediates the relationship between motivation and school success" (Christenson et al., 2012 p.139).

\section{Student Motivation and Engagement in Classroom Context}

The individuals feel the need for autonomy, freedom, and connectedness. 'Autonomy' refers to the option of an individual's own behaviours, 'competence' refers to its adaptation to the world 
and 'relationship' implies becoming connected to others (Ryan \& Deci, 2000). They also stated that students have a different level of motivation. From their theory, the levels of motivation were investigated under three subsections: lack of motivation, extrinsic motivation, and intrinsic motivation. Lack of motivation is a state in which behaviour is not given any significance. Individuals show a specific behaviour of extrinsic motivation owing to outside control, for meeting desires or fulfilling their ego. In intrinsic motivation, on the other hand, people show a specific behaviour because of gratification or curiosity in it, or because of their instinct to succeed (Ryan \& Deci, 2000).

Students who have demonstrated behavioural engagement are known to have good attendance at school, engage in school activities, and respect the rules of the classroom. Students that show emotional engagement feel they belong to the community, show interest in classes or study, and also grow whether positive or negative feelings against school and social influences (Nayir, 2017). In other words, students who integrate behavioural engagement will be known by his environment as the person who can engage in any situation or activity so willingly.

\section{Gamification in Classroom}

Gamification is the use of game design features in non-game contexts. Game features such as point level, display, progress bar, achievement, and scoreboards are used in this study to enable learners to enjoy gaming experience and, in turn, to motivate them to keep learning after the game is over. Efficient difficulty levels and game challenge settings are also considered essential for maximizing the enjoyment of players or learners during the learning process. To control the difficulty level, the difficulty curve model is used to adjust the experience point margin to move from one level to another in the system (Boyinbode, 2018).

Becker and Nicholson (2016) proposed the central components of gamification in the classroom. While no one has not yet completed find the definition of the "game" in classroom context, they claimed most would agree to refer a game, when it includes at least the following aspect (Figure 1):

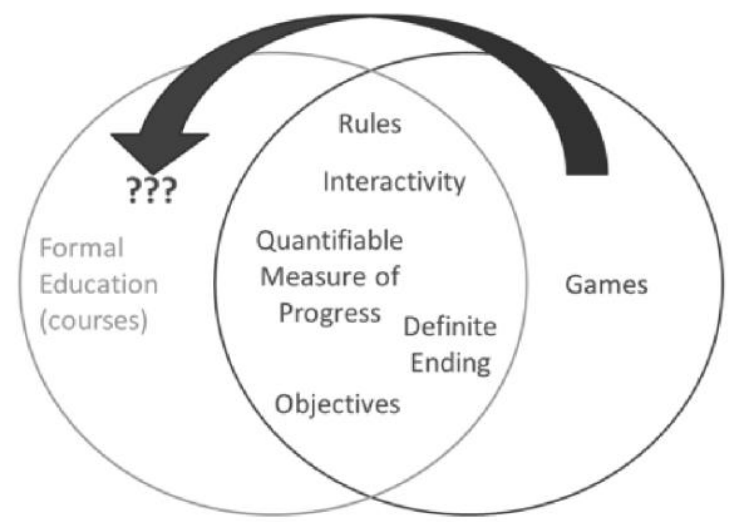

Figure 1. Gamification components (Becker and Nicholson, 2016)

1. Interactivity: if the activity does not involve the student anymore, there is no way to engage, so the game should end.

2. Rules: A system for pre-specifying player action constraints.

3. Goal(s): One or more objectives that players pursue while interacting with the game

60|Language Research in Society Journal Vol 1(1), 2020 
4. Quantifiable measure of progress (or success): The number of teacher's assessments that can be a simple or complicated scoring.

5. Definite ending: Several games do not have clear ending (The Sims, for example), most games have a clear endpoint for example Kahoot! (Becker and Nicholson, 2016).

On the other side, gamification in the education context is an ongoing process that collects the most exciting elements of the game and utilizes them to improve learner motivation and engagement Compared to game-based learning where engagement is short-lived, typically during the duration of the game, the outcomes are understood on the long term (Alsawaier, 2018). Instead, gamification seems to be the key to productive non-traditional interactions between classrooms. Nothing can be more pressuring than a lack of motivation or engagement literally because the classroom does not employ a gamified dynamic with fidelity. Gamification can help teachers to manage and map the motivation and engagement in the classroom (Molumby, 2016).

\section{Meaningful Gamification}

Meaningful gamification includes the usage of ideas such as player-created storylines, authentic play-based encounters, and debriefing to help construct meaning for the user. Some of the ideas listed above, such as empowering players to make a real choice in designing their learning pathways and building failure-safe spaces, will create incentives for realistic gamification. The basic principle is that the program has to provide ways for various categories of learners to make specific links to the basic context (Becker and Nicholson, 2016). They also proposed the six guides to build meaningful gamification, six ways of creating game-based layers (other than rewards) that can be applied to motivate students:

1. Reflection: Provide learners with the ability to examine what they have been introduced to and how they can apply it to their previous experiences.

2. Exposition: Use narratives, either created by the gamification creator or the user, to help students identify links between the meaning and their lives.

3. Choice: Provide learners with decisions on how to interpret the content.

4. Information: Provide meaning and knowledge to learners about their choices and actions to help them create a deeper connection to the real world.

5. Play: Build environments where learners can test, fail, and test again as a way to explore.

6. Engagement: Build bridges between users to help them understand why other students consider the background to participate in and make them interact more likely.

Meaningful gamification is about creating game elements that motivate the user by building his or her intrinsic motivation. When meaningful gamification is correctly used, students can connect the lesson materials in ways that are personally relevant and meaningful to them and they will want to learn rather than be manipulated by rewards.

\section{Self-Determination Theory}

The basic of meaningful gamification is the concept of Self-Determination Theory. Deci and Ryan (2002) stated that this theory a learner to have a positive mental outlook toward engaging with something, they need to feel like they believe they are able to make choices based upon 
their values and interests, that they are confident and effective in engaging with the world, and that they feel that they are connected to other people and have a sense of belonging.

Based on Becker and Nicholson (2016, p. 68), "a key aspect of the concept of play is that play is optional, so for something to truly be play-based, a learner needs to be able to choose not to play. This concept falls in conflict with many classroom settings. If an instructor chooses to add a game layer to the classroom, it can be difficult for a student to opt-out of the game layer and participate in the class more traditionally. Forcing all students to engage with game elements can run counter to the flexibility the game based-system can provide". They also argued that many games are based around the principle of direct competition, and certain gamification aspects, such as leaderboards, are designed on getting players in competition with each other. Both game features point to the fact that some students succeed while others fail. The same ranking that pushes some students to move ahead and excel can also demotivate students who know they're not doing prog (Becker and Nicholson, 2016).

\section{Kahoot!}

Kahoot! is a creative online tool for creating formative language learning assessments, such as quizzes, discussion, and surveys. The feature on the website allows the quiz creator to choose different play modes, either classical (individual) or team mode. This tool can be more fun for game participants and encourages the student to engage in classroom activity actively. Instead, Kahoot! was identified as an online game that tests student's knowledge of the course content. The game is free for both teachers and students, and simply a multimedia tool to participate (Siegle, 2015).

On the top number of answer choices, 'Kahoot!' also provides teachers with the ability to select the amount of the time that students have to respond to each question (Siegle, 2015) for joining the game, students need to put the unique code host from the teacher account and sign in with adding nicknames. While checking the participants to sign in, teachers can also observe for inappropriate names and delete the nickname by clicking the particular nickname. Furthermore, Kahoot! is easy to use in formats such as games and it is already popular with either educators or learners across the country (Singer, 2016). She also reported about 20 million elementary and middle students in the United Kingdom were using Kahoot!. This educational trend includes gamification and student engagement. Instead, the makers of the video game rely on student engagement and interest to keep the popularity of the game spreading (Singer, 2016).

\section{METHOD}

We intend to unravel complex perceptions and issues relating to the use of Kahoot! using an explorative case study under the engagement, motivation, and learning of the students. This method is used to expand the perspectives obtained from literature analysis and to provide fundamental forms of understanding for the phenomena under consideration. We provide details regarding Kahoot!'s design in the following three aspects, our sampling and participants and data processing and analysis (Licorish et al., 2018).

This research involved 35 students in senior high school, who attended the English class in a couple of weeks. The research was developed on the subject of English as a foreign language 
(EFL). The participants were 9 males and 26 females (25.7\% of the participants were male, and 73.3\% were female) The participants are second grade students in senior high school. A questionnaire was used to collect data for this research where participants were asked to answer questions. The questionnaire consists of 12 closed-ended and three open-ended questions. Close-ended questions require respondents to answer by choosing the alternative answer which is available in the form. Meanwhile, open-ended questions lead the respondent to write a short answer in the space in the form.

The questions of the questionnaire were adapted and developed from the instrument proposed by (Khudhair, 2016; Mahmoud \& Tanni, 2014). The followings are the details of the demographic data gathered from the survey:

Table 1. Demographic detail of participants

\begin{tabular}{cccc}
\hline Variable & Value & Frequency & Percentage \\
\hline Gender & Male & 9 & 25.7 \\
& Female & 26 & 73.3 \\
Age & 15 & 17 & 48.6 \\
& 16 & 16 & 45.7 \\
& 17 & 2 & 5.7 \\
Grade & Grade 10 & 31 & 88.6 \\
& Grade 11 & 4 & 11.4 \\
\hline
\end{tabular}

\section{FINDINGS AND DISCUSSION}

This section discusses the data collected in this research regarding the use of Kahoot! as a catalyst for improving students motivation and in-class performance. Based on the data processing, we could divide the data into the following two categories: Students' levels of engagement and motivation and Language learning outcomes.

Table 2. Result for learning motivation item in the survey

\begin{tabular}{llllll}
\hline \multicolumn{1}{c}{ learning motivation item (p) } & $\begin{array}{c}\text { SDA } \\
(\boldsymbol{\%})\end{array}$ & $\begin{array}{c}\mathbf{D} \\
(\boldsymbol{\%})\end{array}$ & $\begin{array}{c}\mathbf{N} \\
(\boldsymbol{\%})\end{array}$ & $\begin{array}{c}\text { A } \\
(\boldsymbol{\%})\end{array}$ & $\begin{array}{c}\text { SA } \\
(\boldsymbol{\%})\end{array}$ \\
\hline 1. Learning English with kahoot! is fun & 2.9 & 0.0 & 22.9 & 25.7 & 40.0 \\
2. English course is so difficult & 8.6 & 11.4 & 60.0 & 20.0 & 0.0 \\
3. I feel bored to have class almost every day & 0.0 & 11.4 & 48.6 & 28.6 & 11.4 \\
4. I feel more active in the class with Kahoot! & 2.9 & 0.0 & 22.9 & 48.6 & 25.7 \\
5. Kahoot! makes me more excited in learning & 5.7 & 0.0 & 40.0 & 42.9 & 11.4 \\
6. I enjoyed the class with Kahoot! & 5.7 & 11.4 & 48.6 & 25.7 & 8.6 \\
7. Kahoot! helps me to have a better interaction & 2.9 & 2.9 & 45.7 & 34.3 & 14.3 \\
between my classmate and the teacher & & & & & \\
8.Kahoot! has positively shaped my perception of & 2.9 & 5.7 & 34.3 & 48.6 & 8.6 \\
online learning & & & & & \\
\hline
\end{tabular}


Table 2. shows the result of questionnaires focus on student engagement and motivation. The table also portrays the percentage of responses by students according to the 5-point Likert scale (i.e., SA = Strongly Agree, A= Agree, $\mathrm{N}=$ Neutral, $\mathrm{D}=$ Disagree, and SDA = Strongly Disagree).

The result in table 2. showed that students' engagement and motivation through classroom activities which implemented Kahoot! was significant. Table 2 showed that most of the students used Kahoot easily! in learning English. It was also reported that Kahoot! facilitated the areas such as:

- Students find that learning English with Kahoot! is fun (40\%)

- Kahoot! leads the student to be more active in the class (48.6\%)

- Students get more excited when the class uses Kahoot! (42.9\%)

- Students have better opportunity to communicate in pair or with the teacher (48\%)

Based on the data above, 10 students (28.6\%) agree and 4 students (11.4\%) strongly agree with the statement (p3) "I feel bored to have class almost every day". It means $40 \%$ of respondents' motivations are in lack of motivation level. When we connect this to the theory, Wigfield and Wagner (2005) found that students with intrinsic motivation have a high level of academic performance and a low level of concern and are more active than extrinsic motivation. Lack of motivation is the bottom one from extrinsic motivation, and the highest is intrinsic motivation. It showed that student motivation needs to be enhanced to reach their academic achievement.

In implementing Kahoot!, this study found that the level of student motivation significantly increased, 9 students $(25.7 \%)$ agree and 14 students (40\%) strongly agree with the statement (p1) " Learning English with Kahoot! is fun". The inherent motivation of students may be proposed to be related to the significance they relate to learning (Nayir, 2017). In other words, the findings of this study revealed that the students were only interested and active in the subjects that were interesting to them. This means Kahoot! enacts as learning media to relate the material, teacher, classroom environment, and the students themselves.

Table 3. Result for learning outcomes item in survey

\begin{tabular}{lccccc}
\hline \multicolumn{1}{c}{ Learning outcomes item (p) } & $\begin{array}{c}\text { SDA } \\
(\boldsymbol{\%})\end{array}$ & $\begin{array}{c}\mathbf{D} \\
\mathbf{( \% )}\end{array}$ & $\begin{array}{c}\mathbf{N} \\
(\mathbf{\%})\end{array}$ & $\begin{array}{c}\text { A } \\
(\boldsymbol{\%})\end{array}$ & $\begin{array}{c}\text { SA } \\
(\boldsymbol{\%})\end{array}$ \\
\hline $\begin{array}{l}\text { 1. Interesting learning media helps me in } \\
\text { understanding material }\end{array}$ & 2.9 & 0.0 & 22.9 & 48.6 & 25.7 \\
$\begin{array}{l}\text { 2. Kahoot! helps me more understand the } \\
\text { materials }\end{array}$ & 5.7 & 5.7 & 42.9 & 40.0 & 5.7 \\
$\begin{array}{l}\text { 3. Kahoot! helps me in mastering the course, } \\
\text { such as vocabularies, the meaning, or grammar } \\
\text { 4. Kahoot! has allowed me to stay focused in } \\
\text { class }\end{array}$ & 2.9 & 8.6 & 48.6 & 34.3 & 5.7 \\
\hline
\end{tabular}

Meanwhile, shedding more light on their capability in mastering the English course, results confirm that; $48.6 \%$ of students reported their support for any new learning media, most of the students also agreed that they could enhance their language on grammar, vocabularies, and 
translation. In comparison, they do a fun activity in the class (34.3\%). The result also showed Kahoot! allowed the students to stay focused in class (42.9\%).

Furthermore, the findings of open-ended questions showed 11 students felt learning in class became more challenging for increasing students' enthusiasm, intensive interaction during the learning process, and the feeling for competition. 11 students also reported the classroom environment became more enjoyable. This game was able to support the learning process by elevating stress providing ease in comprehending the lesson.

\section{Students' Levels of Engagement and Motivation}

Participants reported using Kahoot! promoted interactivity and engagement during classes, through answering questions, contributing to quizzes, and Kahoot! -led discussions. The use of Kahoot! Encouraged greater engagement in class as compared to the traditional classroom where a few students frequently feel bored. The wider involvement of students in the class also promoted a more meaningful engagement to learning. This report indicates that Kahoot!, and the broader use of games and gamification, has a positive influence on classroom interactions, student motivation and engagement, and eventually on their learning (Susilo, 2019).

The data that was collected through point one "Learning English with Kahoot! is fun" got the responses $25.7 \%$, in which students claimed they agree and $40 \%$ strongly agree. It means more than half the number of students is getting motivated in learning English, so they enjoy the learning process, which can be seen from the following excerpts from the survey:

"It makes the good atmosphere in the class" (Student 5)

"High enthusiasm brings a positive effect on the learning process..." (Student 16)

"I focus on the lesson... and try my best on the game" (Student 17)

In line with the students' statements, other researchers claimed that the strategy using online application media based on Kahoot! can increase students ' learning motivation which has been an evidence that English learning outcomes can increase significantly. With the Kahoot! network, student learning performance can be enhanced as proof that English learning results undergo a significant value increase (Susilo, 2019). The present study reveals that gamification can be used for various educational reasons and in all lessons. Students learn topics more easily, and tackle difficult material in a fun way; therefore, it can be concluded that gamification would be an appropriate learning method for English classes. Similar results were also found in a different study. Although numerical games were primarily used, gamification can be applied to many cases in daily life (Becker, 2017). Motivation, one of the most important factors in foreign language learning, is defined as a power that initiates and facilitates the language-learning process. Consistent with Lincorish (2018), in order to discover the responses to the questions and to consider whether they were right or wrong, students developed a deeper comprehension that significantly led to their attention and ability to recall.

\section{Students' Language Learning Outcomes}

Twenty-six of the 35 participants stated that Kahoot! was a useful learning tool and all described Kahoot! as having a positive influence on their learning. Throughout the questionnaires' response, positive references were explained towards how Kahoot! supported their learning. Engaging with Kahoot! during classes helped students not only to remember previously covered

65|Language Research in Society Journal Vol 1(1), 2020 
material but to understand new perspectives and increase their knowledge. In particular, students enjoyed Kahoot! that were relevant to the course, explored complex concepts and offered insight into applications of theory as depicted in the following excerpts:

"Kahoot helps me in mastering material..." (student 21)

"I can get new vocabularies while playing the game" (student 8)

"...it's fun way to learn something" (student 15)

The questionnaire also showed that $48.6 \%$ agree for "Interesting learning media helps me in understanding material" also $34.3 \%$ of students agree in "Kahoot! helps me in mastering the course, such as vocabularies, the meaning, or grammar". Based on Susilo (2019) institutions of higher education need to start using learning technologies, to deliver material for lectures in new ways, to allow students to participate in classes freely and to provide them more concrete forms of study. The present study also provides additional support for a study by Ryan and Deci (2000) which stated that classroom environments need to provide facilities for students to fulfill an intrinsic desire to feel connected, effective and involved as one is introduced to new ideas and new skills. Gaming is a realistic way for educators to provide unique learning opportunities that help students achieve their potential (Siegle, 2015). That means when the three basics of student need has been completed, they can easily get the material or courses that they study. The student has a freedom to express their idea because they can be involved in Kahoot! Anonymously, they can understand whether they answer right or wrong based on the explanation and experience in the game.

\section{CONCLUSION}

This study has revealed the result of students' perception toward the implementation of Kahoot! as online meaningful gamification in the classroom. The gamification-based learning was implemented for two months. From the result of the data analysis, the researcher found out that there has been an interest in understanding how students' motivation and engagement influence their learning. Educational games and gamification in particular contexts are applied to support the development of students' motivational, emotional and social outlook. Students' anonymity were protected when playing Kahoot!, which reduces the risk of their privacy being compromised. To this end, there is a need for deeper insights around the effectiveness of this tool, and particularly for older students. We addressed this gap and conducted interviews with students to understand Kahoot! further, including how this technology informs learning, and the conditions under which it provides the most value to teachers and students. We observed that Kahoot! gave students more opportunities to engage with the teacher, peers and learning content. It also helped in creating a learning experience that was described as "fun", which contributed to useful classroom engagement. Students felt that Kahoot! captured their focus and interest during the course but was also timely for allowing breaks. Our outcomes showed that Kahoot! has been able to motivate students to be engaged in class activities and encourage interaction in the classroom. Students conceded that Kahoot! s use in class had a positive impact on the knowledge and skills they attained. Students noted that the drive to increase their attention and focus and interaction and engagement strongly supported their learning in the course. 


\section{REFERENCES}

Alsawaier, R. S. (2018). The effect of gamification on motivation and engagement. International Journal of Information and Learning Technology, 35(1), 56-79. https://doi.org/10.1108/IJILT-02-2017-0009

Boyinbode, O. (2018). Development of a gamification based English vocabulary mobile learning system. International Journal of Computer Science and Mobile Computing, 7(8), 183-191.

Becker, K., \& Nicholson, S. (2016). Gamification in the classroom: Old wine in New Badges. In K. Schrier (Ed.), Learning, education and games (pp. 61-86). ETC Press.

Becker, Katrin. (2017). Choosing and using digital games in the classroom. Springer International Publishing. Christenson, S. L., Wylie, C., \& Reschly, A. L. (2012). Handbook of research on student engagement. Springer.

Deci, E. L., \& Ryan, R. M. (Eds.). (2002). Handbook of self-determination theory research. University of Rochester Press.

Farooq, M. S., \& Uzair-ul-hassan, M. (2012). Opinion of second language learners about writing difficulties in English language. A Research Journal of South Asian Studies, 27(1), 183-194.

Khan, T. J., \& Khan, N. (2016). Obstacles in learning English as a second language among intermediate students of districts Mianwali and Bhakkar, Pakistan. Open Journal of Social Sciences, 4, 154-162.

Khudhair, N. K. (2016). Investigating Iraqi EFL intermediate schoolteachers' perceptions toward using language games for learning English. AL-USTATH, 1, 69-90.

Licorish, S. A., Owen, H. E., Daniel, B., \& George, J. L. (2018). Students' perception of Kahoot!'s influence on teaching and learning. Research and Practice in Technology Enhanced Learning, 13(9), 1-23.

Lo, J., \& Hyland, F. (2007). Enhancing students' engagement and motivation in writing: The case of primary students in Hong Kong. Journal of Second Language Writing, 16, 219237. https://doi.org/10.1016/j.jslw.2007.06.002

Mahmoud, A. A. A., \& Tanni, Z. A. (2014). Using games to promote students' motivation towards learning English. Al-Quds Open University Journal for Educational \& Psychological Research \& Studies, 2(5), 11-33. https://doi.org/10.12816/0016267

McGonigal, J. (2011). Reality is broken. The Penguin Group. http://jehaynes.files.wordpress.com/2013/02/reality_is_broken.pdf

Molumby, M. J. (2016). Effects of gamification on motivation and engagement in secondary curriculum. 1-36. 
Nayir, F. (2017). The relationship between student motivation and class engagement levels. Egitim Arastirmalari - Eurasian Journal of Educational Research, (71), 59-77. https://doi.org/10.14689/ejer.2017.71.4

Ryan, R. M., \& Deci, E. L. (2000). Intrinsic and extrinsic motivations: Classic definitions and new directions. Contemporary Educational Psychology, 25(1), 54-67. https://doi.org/10.1006/ceps.1999.1020

Siegle, D. (2015). Technology: Learning can be fun and games. Gifted Child Today, 38(3), 192-197. https://doi.org/10.1177/1076217515583744

Singer, N. (2016, April 17). Kahoot app brings urgency of a quiz show to the classroom. New York Times. www.nytimes.com > 2016/04/17 > technology

Susilo, N. (2019). Kahoot apps in ELT context: An alternative learning strategy. ELSYA: Journal of English Language Studies, 1(1), 11-15. https://doi.org/10.31849/elsya.v1i1.2488

Wigfield, A., \& Wagner, A. (2005). Competence, motivation, and identity development during adolescence.

https://www.researchgate.net/publication/284072859_Competence_motivation_and_iden tity_development_during_adolescence 